\title{
Hypertension and intracerebral hemorrhage in Brazzaville*
}

\author{
Thierry Raoul Gombet ${ }^{1,2 \#}$, Paul Macaire Ossou-Nguiet ${ }^{1,3}$, Thibaut Naibe Gankama ${ }^{4}$, \\ Bertrand Fikahem Ellenga-Mbolla ${ }^{1,4}$, Gilbert Fabrice Otiobanda ${ }^{5}$, \\ Karen Obondzo-Aloba ${ }^{3}$, Benjamin Longo-Mbenza ${ }^{6}$ \\ ${ }^{1}$ Department of Medicine, Faculty of Health Sciences of Brazzaville, Brazzaville, Congo \\ ${ }^{2}$ Service of Emergency University Hospital of Brazzaville, Brazzaville, Congo \\ ${ }^{3}$ Service of Neurology University Hospital of Brazzaville, Brazzaville, Congo \\ ${ }^{4}$ Service of Cardiology University Hospital of Brazzaville, Brazzaville, Congo \\ ${ }^{5}$ Service of Reanimation University Hospital of Brazzaville, Brazzaville, Congo \\ ${ }^{6}$ Faculty of Health Sciences, Walter Sisulu University, Mthatha, South Africa \\ Email: raoulgombet@yahoo.fr
}

Received 25 October 2013; revised 26 November 2013; accepted 3 December 2013

Copyright (C) 2013 Thierry Raoul Gombet et al. This is an open access article distributed under the Creative Commons Attribution License, which permits unrestricted use, distribution, and reproduction in any medium, provided the original work is properly cited. In accordance of the Creative Commons Attribution License all Copyrights (C) 2013 are reserved for SCIRP and the owner of the intellectual property Thierry Raoul Gombet et al. All Copyright (C) 2013 are guarded by law and by SCIRP as a guardian.

\section{ABSTRACT}

Hypertension is not only an important risk factor, but also an important cause of spontaneous intracerebral hemorrhage. Its high prevalence in Africa reflects a high incidence of cerebral hemorrhage ranging from $30 \%$ to $60 \%$ against $10 \%$ to $20 \%$ in industrialized countries. The aim of our study was to determine the role of hypertension before the onset of intracerebral hemorrhage and its variations during the first three months. This was a longitudinal study conducted at the University Hospital of Brazzaville from $1^{\text {st }}$ January to $31^{\text {st }}$ August 2012 with all patients admitted for intracerebral hemorrhage. Patients with subarachnoid or pure intraventricular hemorrhage were excluded. The study variables were: history of hypertension, knowledge of its history, treatment, blood pressure on admission and during the first 3 months and the relationship between blood pressure and evolution. Statistical analysis was performed using the software SPSSS 16.1. The significance level was set at $p<0.05$. During the study 261 patients were hospitalized for stroke, of which 82 (31.42\%) were for intracerebral hemorrhage. The mean age was $55 \pm 11$ years and sex ratio of 2 men: 1 woman. Hypertension was found in $80.5 \%$ of cases, of which $65.2 \%$ had known hypertension, but $82.6 \%$ had discontinued treatment. The mean systolic blood pressure was 194 $\pm 41 \mathrm{~mm} \mathrm{Hg}$ and diastolic $104 \pm 20 \mathrm{~mm} \mathrm{Hg}$. The location was deep in $85.71 \%$. The normalization of blood

\footnotetext{
*Conflict of interest: The authors declare no conflict of interest

${ }^{*}$ Corresponding author.
}

pressure was obtained from the second week. After adjusting for confounders using logistic analysis, only uncontrolled hypertension was associated significantly and independently associated with a higher mortality rate $(p=0.042)$.

Keywords: Hypertension; Cerebral Hemorrhage; Brazzaville

\section{INTRODUCTION}

The hemorrhagic stroke or intra cerebral hematoma (ICH) is the extravasation of blood into the brain parenchyma. Its incidence is 9 - 15 cases per 100.000 persons [1]. There are racial variations of hypertension prevalence which is higher among blacks and Asians than the rest of the world [2,3]. It represents $10 \%$ to $30 \%$ of stroke $[4,5]$. $\mathrm{ICH}$ is the most severe and the most deadly subtype. Chronic hypertension is not only the first risk factor, but also the primary cause of $\mathrm{ICH}$ in $60 \%$ of cases [6,7]. Arteriosclerosis and micro-Charcot-Bouchard aneurysms which may rupture at deep penetrating arterioles explain the hematoma $[8,9]$. A high blood pressure is regularly observed in the acute phase of ICH [10], most often associated with an increase in the volume of hematoma, or a poor prognosis [6]. Although studies have been conducted on the management of blood pressure in ICH [11, 12], however, in sub-Saharan Africa, the prevalence of hypertension is high with a lower prevalence of stroke in general populations [13].

In Brazzaville (Congo), 32.5\% of the population are hypertensive [14]. Furthermore, stroke is a frequent reason 
for hospitalization, and represents the first hypertensive emergency in Brazzaville University Hospital [15].

The aim of our study was to assess the role of hypertension before the onset of ICH, and its variations during the first three months, as well as its impact on prognosis.

\section{METHODS}

This is a longitudinal study conducted at the University Hospital of Brazzaville, services of Neurology, Emergency and Intensive Care Unit from $1^{\text {st }}$ January to $31^{\text {st }}$ August 2012 for a period of 8 months. The study population consisted of patients admitted for ICH in these services. We included all patients hospitalized for hemorrhagic stroke confirmed by $\mathrm{CT}$ scan without contrast injection, regardless of age and sex. Informed consent was obtained either from the patient when he was not conscious and aphasic, either from a close family member when the patient was unconscious or in case of severe aphasia. We excluded all patients hospitalized for suspicion of stroke not confirmed by brain CT-scan, patients with normal scan or signs of ischemic stroke, isolate subarachnoid hemorrhage, intraventricular hemorrhage, hemorrhagic infarction, head trauma, brain tumorinduced hemorrhage, or patients in whom informed consent was not obtained. The diagnosis of hemorrhagic stroke was confirmed by the presence of an intraparenchymal hyperdensity with or without spontaneous ventricular break. The study variables were: age, sex, vascular risk factors such as the history of hypertension defined as systolic blood pressure(SBP or PAS in french) $\geq$ $140 \mathrm{mmHg}$ and/or diastolic blood pressure (DBP or PAD in French) $\geq 90 \mathrm{mmHg}$ or the existence of antihypertensive treatment in. Knowledge of hypertension, its duration, the time between ICH onset and the time of hospitalization, adherence, control, daily monitoring, the location and the site of the hematoma, the severity of hypertension at admission, the initial severity stroke by the NIHSS score, the progression of the disease and outcomes(death or survivorship) of patient. The evolution was evaluated on the third day (D3 or J3 in French) on the seventh day (D7 or J7 in French), the fourteenth day (D14 or J14 in French), one month (M1), two months (M2) and three months (M3 or J90 in French).

\section{STATISTICAL ANALYSIS}

The data collected were entered in Excel, and then analyzed using the SPSSS version 16.1 on Windows. The qualitative variables were expressed as frequency (n) or proportions (\%) and quantitative variables as mean \pm standard deviation(SD). The chi-square test was used to compare proportions, while Student-t test was used to compare means. Statistical significance was set for the probability $\mathrm{p} \leq 0.05$.

\section{RESULTS}

Of 689 patients in these services, 261(37.88\%) were admitted for stroke, among them $86(32.95 \%)$ cases of ICH with 82 cases of intra-parenchymal hemorrhage (31.42\%) and 4 cases $(1.53 \%)$ of subarachnoid hemorrhage.

A total of 82 cases of ICH, there were $51(63.4 \%)$ men and $31(36.6 \%)$ women with a sex ratio of 2 men: 1 woman. The mean age of patients was $55 \pm 11$ years (range 26 to 83 years).

Table 1 shows the frequency of various risk factors.

In terms of frequency of risk factors, hypertension was the first with $80.5 \%$ of patients. Twenty-three hypertensive patients were adherent to hyp 19 (82.6\%) had discontinued treatment before hospitalization. Hypertension was found in $80.5 \%$ of cases whose $65.2 \%$ had known hypertension but $82.6 \%$ had discontinued treatment. Only $4(17.4 \%)$ had not interrupted the assessment of the longitudinal follow-up. On admission, the mean systolic blood pressure (SBP) was $194.51 \pm 41.31 \mathrm{mmHg}$, with a range from 100 to $270 \mathrm{mmHg}$. Diastolic blood pressure (DBP) averaged $104.51 \pm 20.44 \mathrm{mmHg}$, with a range from 70 to $170 \mathrm{mmHg}$. Figure 1 shows the levels of blood pressure on admission.

In terms of initial severity, the NIHSS score at admission average was $14.9 \pm 7.3$, with a range from 2 to 30 .

The electrocardiogram had revealed left ventricular hypertrophy (LVH) in 42 (63.6\%) on 66 hypertensive.

The average time for completion of the CT scan was $2.4 \pm 2$ days, with ranging from 1 to 14 days.

Ventricular break of hemorrhage was noted in 24 (29.4\%) patients. The hematoma was supratentoriel in $92.7 \%$ and $6.1 \%$ in infratentorial. The average volume of the hematoma was $24 \pm 17 \mathrm{ml}$.

The deep site was the most frequent (55\%) followed by lobar site in 29\% (Figure 2).

The management of blood pressure involved the administration of intravenous nicardipin for all patients with blood pressure $\geq 160 / 110 \mathrm{mmHg}$, and all known hypertensive patient were treated by combination of Enalapril and Hydrochlorothiazide.

Figure 3 depicts the changes of SBP and DBP across the time of the monitoring which showed a constant normalization of blood pressure from the second week to the end of the follow-up (3 months).

The incident mortality rate was $37.8 \%(\mathrm{n}=31 / 82$ patients). After adjusting for age, sex, history of hypertension, and initial severity, multivariate analysis identified only uncontrolled hypertension was associated significantly and independently associatedwith higher mortality rate $(\mathrm{p}=0.042)$ (Table 2$)$.

\section{DISCUSSION}

We conducted a prospective study, including all patients 
Table 1. Frequency of risk factors.

\begin{tabular}{ccc}
\hline Risk Factors & Number & $\%$ \\
\hline Hypertension & 66 & 80.5 \\
Sedentarity & 49 & 59.8 \\
Smoking & 13 & 15.9 \\
Diabetes & 2 & 2.4 \\
Alcohol & 56 & 68.3 \\
Hypercholesterolemia & 28 & 65.1 \\
\hline
\end{tabular}

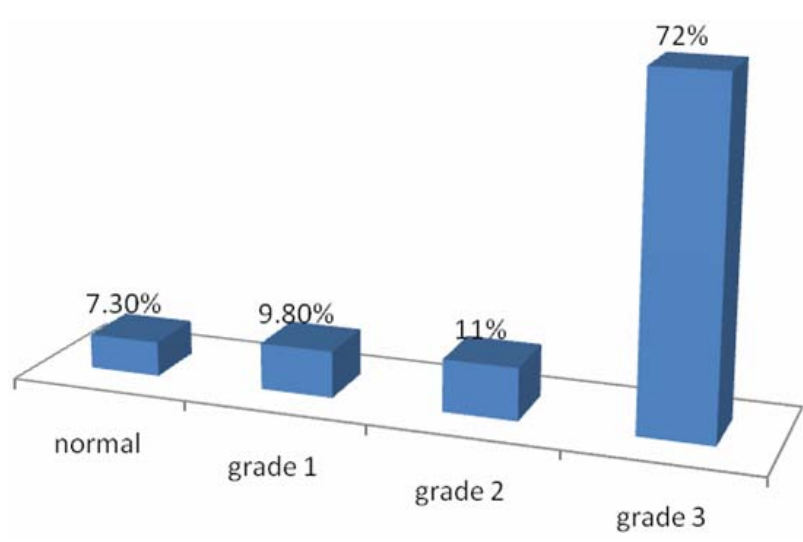

Figure 1. Different levels of blood pressure at admission.

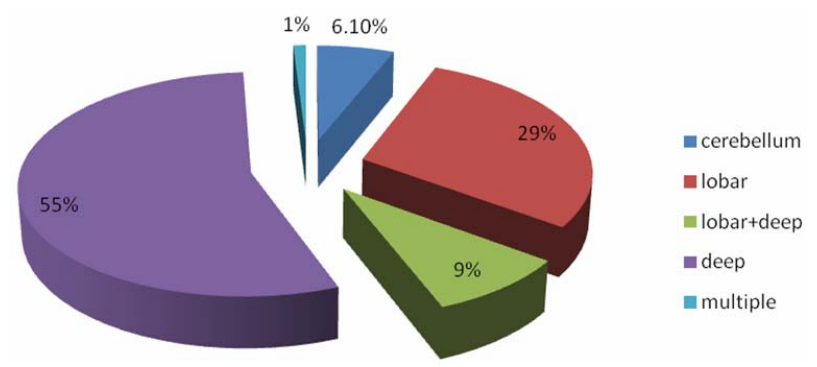

Figure 2. Distribution of bleeding anatomical sites of the brain.

admitted to University Hospital of Brazzaville for ICH. Likewise, this study involved a small number of patients. But it allowed us to estimate the impact of uncontrolled hypertension in cerebral hemorrhage in Central Africa.

The ICH rate was estimated at $32.95 \%$ during the study period. Our results were different from those of the most Western literature where the incidence of cerebral hemorrhage is between $10 \%$ and $20 \%$ [16,17]. This difference can be explained in two ways, first, the fact that our study was purely performed in hospital, so that our findings cannot be generalized to the Congolese population. It may not reflect the true incidence. Second, the higher frequency ofICH is well known among black individuals $[5,18]$. In INTERSTROKE multicenter study conducted in 22 countries, O'Donnell et al. [19] reported a frequency of $9 \%$ in the industrialized countries, $22 \%$ in South East Asia, 26\% in South America and 34\% in Africa. Belo et al. [20] in a study of the characteristics of stroke in Black Africans from Togo, found incidences of ICH between
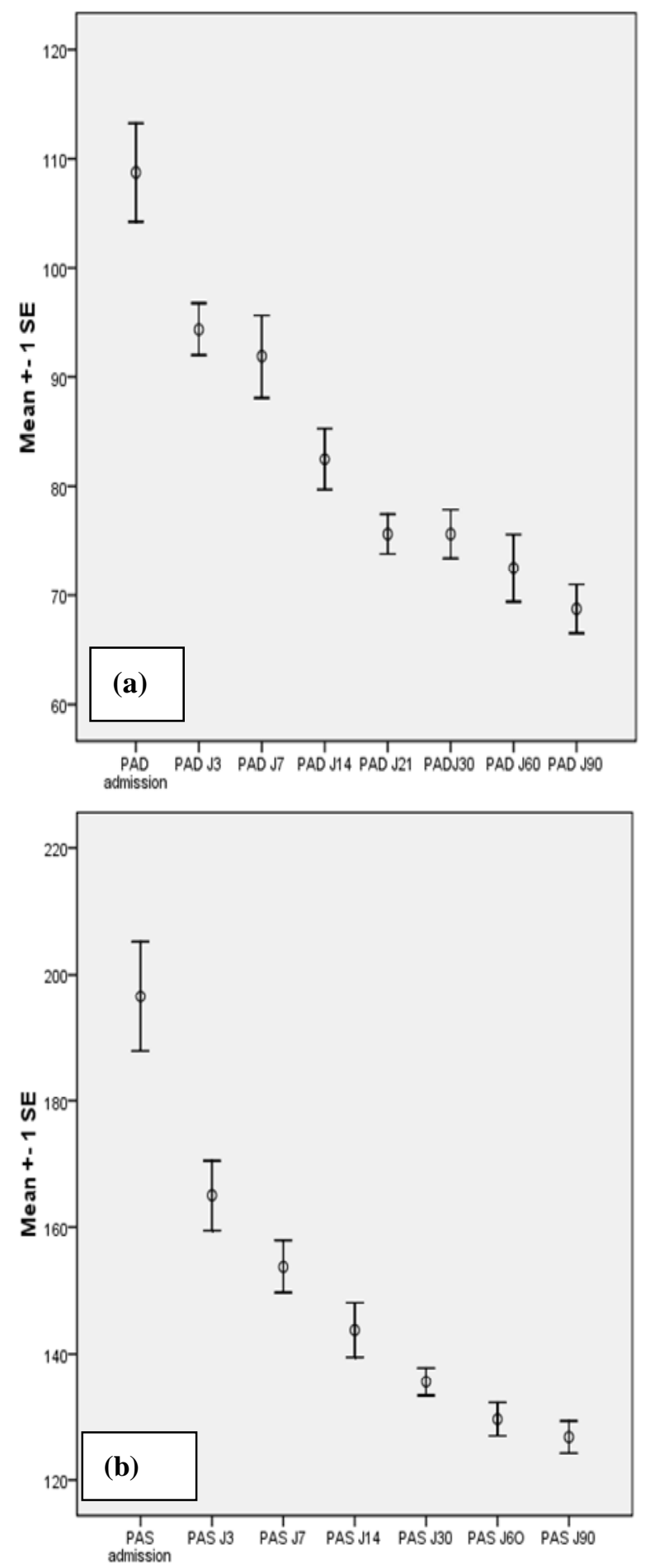

Figure 3. Changes in blood pressure during the first three months, SBP (a) and DBP (b). Legend: PAD = DBP, PAS = $\mathrm{SBP}, \mathrm{J}=\mathrm{D}$ (day).

$28 \%$ and $60 \%$. Our hospital frequency of ICH $(32.95 \%)$ was consistent with that interval. from Sagi et al. in different African countries[21] Adoukonou et al. [13] showed 12 African studies report a frequency ICH ranging from $21 \%$ to $60.1 \%$ which is consistent with our 
Table 2. Associations between variables and outcomes.

\begin{tabular}{|c|c|c|c|c|}
\hline Parameters & $\begin{array}{l}\text { Population } \mathrm{n}(\%) \text { or } \\
\text { mean } \pm \mathrm{SD}\end{array}$ & $\begin{array}{l}\text { Death } \mathrm{n}(\%) \\
\text { mean } \pm \mathrm{SD}\end{array}$ & $\begin{array}{c}\text { Survivor } \mathrm{n}(\%) \\
\text { mean } \pm \mathrm{SD}\end{array}$ & P-Value \\
\hline Hypertension & $66(80.5)$ & $25(37.9)$ & $41(62.1)$ & 0.607 \\
\hline Alcohol & $56(69.1)$ & $22(39.3)$ & $34(60.1)$ & 0.490 \\
\hline Sedentarity & $49(59.8 \%)$ & $20(40.8 \%)$ & $29(59.2)$ & 0.327 \\
\hline Smoking & 13(15.9) & $6(46.2)$ & $7(53.8)$ & 0.352 \\
\hline Diabetes & $2(2.4)$ & $2(100)$ & $0(0)$ & 0.140 \\
\hline SBP & $194.5 \pm 41,3$ & $190.3 \pm 34,1$ & $197 \pm 45.2$ & 0.042 \\
\hline DBP & $104.5 \pm 20.4$ & $104.5 \pm 19.2$ & $104.5 \pm 21.4$ & 0.847 \\
\hline $\begin{array}{l}\text { Location } \\
\text { - Supratentorial } \\
\text { - Supra + infra } \\
\text { - Infratentorial }\end{array}$ & $\begin{array}{c}76(92.7) \\
1(1.2) \\
5(6.1)\end{array}$ & $\begin{array}{c}30(39.5) \\
0(0) \\
1(20)\end{array}$ & $\begin{array}{c}46(60.5) \\
1(100) \\
4(80)\end{array}$ & 0.504 \\
\hline $\begin{array}{l}\text { Site } \\
\text { - Lobar } \\
\text { - Deep } \\
\text { - Lobar and deep } \\
\text { - Cerebellum } \\
\text { - } \text { Multiple }\end{array}$ & $\begin{array}{c}24 \\
45 \\
7 \\
5 \\
1\end{array}$ & $\begin{array}{c}9 \\
18 \\
3 \\
1 \\
0\end{array}$ & $\begin{array}{c}15 \\
27 \\
4 \\
4 \\
1\end{array}$ & 0.835 \\
\hline
\end{tabular}

results. The high frequency and observed is related to the prevalence of hypertension in Brazzaville which varies between $32.6 \%$ and $43 \%$ [14,22], hypertension is not only a risk factor, but the main cause of ICH. Its frequency in stroke patients ranges from $40 \%$ to over $80 \%$ [21]. Also this increase in frequency reflects the systematic implementation of a brain scan for suspected stroke as also reported by Ossou-Nguiet [23].

The mean age of our patients was $55 \pm 11$ years and very similar to those of Ossou-Nguiet et al. [24], Raveloson et al. in Madagascar [25], Benedict et al in Djibouti [26], and Sagi et al. across several sub-Saharan African countries [21].

Regarding hypertension, $80.5 \%$ of our patients had a previous hypertension. Our results were similar with most African and Western studies as reported by Manno et al. [17], Ossou-Nguiet et al. [24], Raveloson et al. [25], Shoemaker et al. [27], Chuang et al. [28], and Li et al. [29].

In our study, $34.80 \%$ of patients did not know their hypertension status. This high rate of ignorance of hypertension reflects the weaknesses of management awareness and screening of hypertension which are essential way to fight against hypertension. Our results confirmed those of Raveloson et al. with 70.59\% ignorant of hypertension [25]. The history of hypertension did not influence the prognosis. Our results were very similar to those of Ossou-Nguiet et al. in Brazzaville [24], and Cheung and Zouin China [30]. However, Chuang et al. in Taiwan showed that hypertension was associated with earlier death with only $29.4 \%$ hypertensives among all participants [28]. This difference could be explained by the magnitude (over $80 \%$ ) of hyperten- sion in the study populations from Ossou-Nguiet et al [24], Cheung et al. [30], and the present study.

The response rate to the steps of the monitoring was low and estimated only $34.90 \%$ in the present study and similar with that of $29.1 \%$ reported by Ravelosonin Madagascar [25]. Of 39 hypertensive patients, more than half $(59 \%)$ received treatment against hypertension. However, the number of untreated hypertension is relatively large (41\%), highlighting the lack of communication, the denial or offers of health care, but also low economic level. The present percentage of treated hypertensive obtained in our study exceeded that of $29.4 \%$ observed by Raveloson [25].

With a mean SBP of $194.5 \mathrm{mmHg}$ and a mean DBP $104.5 \mathrm{mmHg}$ fromour study was consistent with that of Cheung and Zouin China [30] in China and Matsoukawa et al. in Japan [31]. The later pressures were higher than those found by Chuang et al. in Taiwan [28]. Both ethnic and environmental factors may explain severity of hypertension in black Africans and Indians [32].

The increase in SBP was significantly associated with death as evidenced by Ossou Nguiet et al. [24], Hu et al. [32] and Béjot et al. [33]. The mean NIHSS score at admission was $14.9 \pm 7.3$. Our results corroborate those of Dowlatshahi [34] who obtained an average of 13. A high NIHSS score (over 20) was a predictor of mortality at 30 days and poor recovery at 3 months as reported by some authors [24,30]

The ventricular hypertrophy found in our hypertensive patients was the main complication and well established as one of coronary heart disease and should be recognized in the management of hypertension [35].

The supratentorial location represented $92.7 \%$ against 
$6.1 \%$ infratentorial location. These results were consistent with most studies [36]. Indeed the main causes of cerebral hemorrhage including hypertension, arteriovenous malformations and amyloid angiopathy induce more supratentorial hematoma than infratentorial hematoma.

The deep site was most frequent $(55 \%)$ and followed by lobar site representing $29 \%$ and cerebellar site for 6.1 $\%$. This distribution was consistent with data from the literature $[29,36]$. The deep location is the predilection of the hematoma related to hypertension at determining micro-aneurysms of perforating arteries. The location of the hematoma did not influence the prognosis as also reported by Cheung and Zou [30] and by Godoy [36]. Ventricular break frequently encountered was observed in $29.4 \%$. These data are congruent with those of Raveloson et al [25], Dowlatshahi et al. [34] who found $36.4 \%$ and $33 \%$. It was associated with death $(\mathrm{p}=0.044)$ as described in the literature $[30,36]$, respectively.

The mortality rate at 30 days ( 1 month) was $35.4 \%$. This result is in the range of mortality rates described in Black Africansin Togo [20] and France [27,36]. However, the mortality rate reported in this work was lower than that found by Raveloson et al. in Madagascar [25]. The difference in these mortality rates is due to the fact that these authors have worked on too small samples of 34 patients. The mortality rate at 48 hours was $15.9 \%$. He corresponded almost to half of the 30-day mortality. The mortality rate at 7 and 14 days was double the rate of 48 precisely for $25.7 \%$ and $34.2 \%$, respectively. Our results differed from those of Ossou-Nguiet et al. in Congo and who found a mortality rate at 14 days for $13 \%$ in the Neurology Department [24]. This difference is explained by the fact that his work had an inclusion bias. We have included not only patients from Neurology but also in Intensive Care and Emergency, and the hospital system in our context is organized so that patients a severe stroke are often directly oriented to intensive care not in neurology service.

\section{CONCLUSION}

Hypertension remains a major risk factor of mortality and most frequently found in the intracerebral hemorrhage. In sub-Saharan Africa, as in the Congo, its high prevalence contrasts with the weakness of management awareness, support and especially patient education. Better control of blood pressure would not only reduce the incidence of cerebral hemorrhage, but also reduce mortality.

\section{REFERENCES}

[1] Benatru, I., Rouaud, O., Durier, J., Contegal, F., Couvreur, G., Bejot, Y., et al. (2006) Stable stroke incidence rates but improved case fatality in Dijon, France, from 1985 to
2004. Stroke, 37, 1674-1679. http://dx.doi.org/10.1161/01.STR.0000226979.56456.a8

[2] Gombet, T., Steichen, O., Plouin, P.F., Richet, G., Touze, J.E. and Doury, P. (2007) Maladie hypertensive des personnes âgées nées en Afrique subsaharienne adressée à un service spécialisé: Etude transversale comparative. Bulletin de l'Academie Nationale de Medecine, 191, 1745-1755.

[3] Rincon, F., Lyden, P. and Mayer, S.A. (2012) The epidemiology of intracerebral hemorrhage in the United States from 1979 to 2008. Springer Science, 77, 524-532.

[4] Broderick, J.P., Connolly, S., Feldmann, E., Hanley, D., Kase, C., Krieger, D., et al. (2007) Guidelines for the management of spontaneous intracerebral hemorrhage in adults: 2007 update: A guideline from the American Heart Association/American Stroke Association Stroke Council, High Blood Pressure Research Council, and the Quality of Care and Outcomes in Research Interdisciplinary Working group. Stroke, 38, 2001-2023. http://dx.doi.org/10.1161/STROKEAHA.107.183689

[5] Markus, H.S., Khan, U., Birns, J., Evans, A., Kalra, L., Rudd, A.G., et al. (2007) Differences in stroke subtypes between black and white patients with stroke. Circulation, 116, 2157-2164.

http://dx.doi.org/10.1161/CIRCULATIONAHA.107.6997 85

[6] Mayer, S.A. and Rincon, F. (2005) Treatment of intracerebral haemorrhage. The Lancet Neurology, 4, 662672. http://dx.doi.org/10.1016/S1474-4422(05)70195-2

[7] Testai, F.D. and Aiyagari, V. (2008) Acute hemorrhagic stroke pathophysiology and medical interventions: Blood pressure control, management of anticoagulant-associated brain hemorrhage and general management principles. Neurologic Clinics, 26, 963-985. http://dx.doi.org/10.1016/j.ncl.2008.06.001

[8] Fisher, C.M. (2003) Hypertensive cerebral hemorrhage. Demonstration of the source of bleeding. Journal of Neuropathology \& Experimental Neurology, 62, 104-107.

[9] Sutherland, G.R. and Auer, R.N. (2006) Primary intracerebral hemorrhage. Journal of Clinical Neuroscience, 13, 511-517. http://dx.doi.org/10.1016/j.jocn.2004.12.012

[10] Qureshi, A.I., Ezzeddine, M.A., Nasar, A., Suri, M.F., Kirmani, J.F., Hussein, H.M., et al. (2007) Prevalence of elevated blood pressure in 563,704 adult patients with stroke presenting to the ED in the United States. American Journal of Emergency Medicine, 25, 32-38. http://dx.doi.org/10.1016/j.ajem.2006.07.008

[11] Qureshi, A.I. (2007) Antihypertensive treatment of acute cerebral hemorrhage (ATACH): Rationale and design. Neurocritical Care, 6, 56-66. http://dx.doi.org/10.1385/NCC:6:1:56

[12] Anderson, C.S., Huang, Y., Wang, J.G., Arima, H., Neal, B., Peng, B., et al. (2008) Intensive blood pressure reduction in acute cerebral haemorrhage trial (INTERACT): A randomised pilot trial. The Lancet Neurology, 7, 391-399. http://dx.doi.org/10.1016/S1474-4422(08)70069-3

[13] Adoukonou, T.A., Vallat, J.M., Joubert, J., Macian, F., Kabore, R., Magy, L., Houinato, D. and Preux, P.M. (2010) Management of stroke in sub-Saharan Africa: Current 
issues. Revue Neurologique, 166, 882-893. http://dx.doi.org/10.1016/j.neurol.2010.06.004

[14] Kimbally-Kaky, G., Gombet, T., Bolanda, D., Voumbo, Y., Okili, B., Ellenga-Mbolla, B. et al. (2006) Prévalence de l'HTA à Brazzaville. Cardiologie Tropicale, 32, 4346.

[15] Ellenga-Mbolla, B.F., Gombet, T.R., Mahoungou-Guimbi, K.C., Otiobanda, G.F., Ossou-Nguiet, P.M., Ikama, M.S., KimballyKaky, G. and Etitiele, F. (2011) Les urgences hypertensives au Centre Hospitalier et Universitaire de Brazzaville (Congo). Médecine Tropicale, 71, 97-98.

[16] Elliott, J. and Smith, M. (2010) The acute management of intracerebral hemorrhage: A clinical review. Anesthesia \& Analgesia, 110, 1419-1427. http://dx.doi.org/10.1213/ANE.0b013e3181d568c8

[17] Manno, E.M. (2012) Update on intracerebral hemorrhage. CONTINUUM: Lifelong Learning in Neurology, 18, 598610. http://dx.doi.org/10.1212/01.CON.0000415430.99394.3e

[18] Lotufo, P.A., Goulart, A.C. and Bensenor, I.M. (2007) Race, gender and stroke subtypes mortality in Sao Paulo, Brazil. Arquivos de Neuro-Psiquiatria, 65, 752-757.

[19] O’Donnell, M.J., Xavier, D., Liu, L., Zhang, H., Chin, S.L., Rao-Melacini, P., et al. (2010) (INTERSTROKE investigators). Risk factors for ischaemic and intracerebral haemorrhagic stroke in 22 countries (the INTERSTROKE study): A case-control study. The Lancet, 376, 112-123. http://dx.doi.org/10.1016/S0140-6736(10)60834-3

[20] Belo, M., Balogou, A.A.K., Goeh-Akue, E., Sognigbe, N., Kumako, V., Djibril, M., et al. (2007) Particularitée des accidents vasculaires cérébraux au Togo et en Afrique Noire. Journal de la Recherche Scientifique de l'Universite de Lome, 9, 21-27.

[21] Sagui, E. (2007) Les accidents vasculaires cérébraux en Afrique subsaharienne. Médecine Tropicale, 6, 596-600.

[22] Lessive, P., Mughnetsyan, V. and Kessy, G.S. (2009) Etude épidémiologique lors d'une campagne de dépistage du diabète, de l'hypertension et de l'obésité andrö̈de à Brazzaville. Medecine des Maladies Metaboliques, 3, 438441.

[23] Ossou-Nguiet, P.M., Otiobanda, G.F., ObondzoAloba, K., Ellenga-Mbolla, B.F., Bandzouzi-Ndamba, B. and Makosso, E. (2013) Contribution on epidemiology and management of stroke in a central African country. International Journal of Stroke, 8, E27. http://dx.doi.org/10.1111/ijs.12118

[24] Ossou-Nguiet, P.M., Otiobanda, G.F., Bandzouzi-Ndamba, B., Ellenga-Mbolla, B.F., Mahoungou-Guimbi, K.C., Gnonlonfoun, D., et al. (2011) Devenir des patients ayant présenté une hémorragie cérébrale au CHUB de Brazzaville. RAMUR Tome, 16, 37-43.

[25] Raveloson, N.E., Zodali, N., Rakotoarivoni, S.T., Mbolambena, R.L. and Randriamiarana, J.M. (2011) Aspects épidémio-cliniques, évolutifs et tomodensitométriques des accidents vasculaires cérébraux hémorragiques. $R e$ - vue d'Anesthésie-Réanimation et de Médecine d'Urgences, 3, 15-19.

[26] Benoît, A., Raynaud, A., Coton, L., Petitjans, F., Hassan, A., Ilah, A., et al. (2009) Morbi-mortalité des accidents vasculaires cérébraux hémorragiques. Médecine Tropicale, 69, 41-44.

[27] Cordonnier, C., Rutgers, M.P., Dumont, F., Pasquini, M., Le Jeune, J.P., Garrigue, D., et al. (2009) Intracerebral haemorrhages: Are there differences in baseline characteristics and intra-hospital mortality between hospital and population-based registred? Journal of Neurology, 256, 198-202. http://dx.doi.org/10.1007/s00415-009-0030-3

[28] Chuang, Y.C., Chen, Y.M., Peng, S.K. and Peng, S.Y. (2009) Risk stratification for predicting 30-day mortality of intracerebral hemorrhage. International Journal for Quality in Health Care, 21, 441-447. http://dx.doi.org/10.1093/intqhe/mzp041

[29] Li, Q., Qin, X.Y., Zhang, J.H. and Yang, J. (2011) Prognosis study of 324 cases with spontaneous intracerebral hemorrhage in Chongqing, China. Acta Neurochirurgica Supplementum, 111, 399-402. http://dx.doi.org/10.1007/978-3-7091-0693-8 68

[30] Cheung, R.T. and Zou, L.Y. (2003) Use of the original, modified or new intracerebral hemorrhage score to predict mortality and morbidity after intracerebral hemorrhage. Stroke, 34, 1717-1712. http://dx.doi.org/10.1161/01.STR.0000078657.22835.B9

[31] Matsukawa, H., Shinoda, M., Fujii, M., Takahashi, O., Yamamoto, D., Murakata, A., et al. (2012) Relationships among hematoma diameter, location categorized by vascular territory, and 1-year outcome in patients with cerebellar hemorrhage. World Neurosurgery, 77, 507-511. http://dx.doi.org/10.1016/j.wneu.2011.05.018

[32] Hu, X., Zhang, J.H. and Qin, X. (2011) Risk factors of early death in patients with hypertensive intracerebral hemorrhage during hospitalisation. Acta Neurochirurgica Supplementum, 11, 387-391. http://dx.doi.org/10.1007/978-3-7091-0693-8 66

[33] Bejot, Y., Rouaud, O., Benatru, I., Froment, A., Couvreur, G., Cailler, M., et al. (2008) Les apports du registre dijonnais des accidents vasculaires cérébraux en 20 ans d'activité. Revue Neurologique, 164, 138-147. http://dx.doi.org/10.1016/j.neurol.2007.06.003

[34] Dowlatshahi, D., Demuchuk, A.M., Flaherty, M.L., Ali, M., Lyden, P.L., Faan, E.E., et al. (2011) Defining hematoma expansion in intracerebral hemorrhage: Relationship with patient outcomes. Neurology, 76, 1238-1244. http://dx.doi.org/10.1212/WNL.0b013e3182143317

[35] Gosse, P. and Cremer, A. (2011) Hypertrophie ventriculaire gauche chez l'hypertendu: Mise au point et point de vue. AMC-Pratique, 202, 16-20.

[36] Godoy, D.A., Piñero, G. and Di Napoli, M. (2006) Predicting mortality in spontaneous intracerebral hemorrhage: Can modification to original score improve the prediction? Stroke, 37, 1038-1044.

http://dx.doi.org/10.1161/01.STR.0000206441.79646.49 